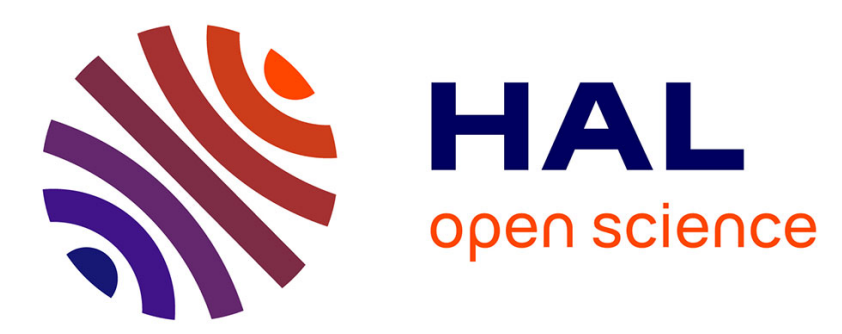

\title{
Friction factor and heat tranfer coefficient of R134a liquid flow in mini-channels
}

\author{
Bruno Agostini, Barbara Watel, André Bontemps, Bernard Thonon
}

\section{To cite this version:}

Bruno Agostini, Barbara Watel, André Bontemps, Bernard Thonon. Friction factor and heat tranfer coefficient of R134a liquid flow in mini-channels. Applied Thermal Engineering, 2003, 22, pp.18211834. 10.1016/S1359-4311(02)00108-4 . hal-00184134

\section{HAL Id: hal-00184134 \\ https://hal.science/hal-00184134}

Submitted on 19 Feb 2020

HAL is a multi-disciplinary open access archive for the deposit and dissemination of scientific research documents, whether they are published or not. The documents may come from teaching and research institutions in France or abroad, or from public or private research centers.
L'archive ouverte pluridisciplinaire HAL, est destinée au dépôt et à la diffusion de documents scientifiques de niveau recherche, publiés ou non, émanant des établissements d'enseignement et de recherche français ou étrangers, des laboratoires publics ou privés. 


\title{
Friction factor and heat transfer coefficient of R134a liquid flow in mini-channels
}

\author{
Bruno Agostini ${ }^{\mathrm{a}, \mathrm{b}, *}$, Barbara Watel ${ }^{\mathrm{b}, \mathrm{c}}$, André Bontemps ${ }^{\mathrm{b}, \mathrm{c}}$, Bernard Thonon ${ }^{\mathrm{b}}$ \\ ${ }^{a}$ ADEME, 2 Square Lafayette, 49004 Angers, France \\ ${ }^{\mathrm{b}}$ CEA Grenoble, GRETh, 17 rue des Martyrs, 38054 Grenoble, France \\ ${ }^{\mathrm{c}}$ LEGI/GRETh, Université Joseph Fourier, 17 rue des Martyrs, 38054 Grenoble, France
}

This article presents an experimental study of friction factor and heat transfer coefficient for a vertical liquid up-flow of R134a. A flat aluminium multiport extruded tube composed of 11 parallel rectangular channels $(3.28 \mathrm{~mm} \times 1.47 \mathrm{~mm})$ with hydraulic diameter of $2.01 \mathrm{~mm}$ was used. Mass flux ranges from 28 to $800 \mathrm{~kg} \mathrm{~m}^{-2} \mathrm{~s}^{-1}$ and heat flux from 0.84 to $22 \mathrm{~kW} \mathrm{~m}^{-2}$. Working pressure is around $2000 \mathrm{kPa}$ and inlet subcooling around $70 \mathrm{~K}$. The results were compared with those found in the literature for conventional tubes and mini-channels, and discussed.

Keywords: Mini-channels; Friction factor; Heat transfer coefficient; Air-conditioning; Compact heat exchanger

\section{Introduction}

New environmental policies on global warming require that emissions of gases with significant greenhouse effect should be decreased. The use of mini-channel heat exchangers (hydraulic diameter about $1 \mathrm{~mm}$ ) contributes to achieve this purpose thanks to higher heat transfer coefficients, thermal efficiency and a lower required fluid mass. They are widely used in condensers for automobile air-conditioning and will be used in evaporators and domestic air-conditioning.

\footnotetext{
* Corresponding author. Address: CEA Grenoble, GRETh, 17 rue des Martyrs, 38054 Grenoble, France. Tel.: +33-438-78-32-77; fax: +33-4-38-78-55-77.

E-mail address: bruno.agostini@laposte.net (B. Agostini).
} 


\section{Nomenclature}

$A_{\text {al }} \quad$ aluminium cross-section $\left(\mathrm{m}^{2}\right)$

$B i \quad$ Biot number

$c_{p} \quad$ specific heat $\left(\mathrm{J} \mathrm{kg}^{-1} \mathrm{~K}^{-1}\right)$

$D_{\mathrm{h}}=(2(l h) /(l+h))$ hydraulic diameter $(\mathrm{m})$

$e \quad$ wall thickness (m)

$4 f$ friction factor

Gr Grashof number

$h \quad$ channel height (m)

$L \quad$ test section length (m)

$L_{\mathrm{a}} \quad$ adiabatic length (m)

$L_{\mathrm{j}} \quad$ heated length (m)

$l \quad$ channel width (m)

$\dot{M} \quad$ mass flow rate $\left(\mathrm{kg} \mathrm{s}^{-1}\right)$

$\dot{m} \quad$ mass flux $\left(\mathrm{kg} \mathrm{m}^{-2} \mathrm{~s}^{-1}\right)$

$N \quad$ number of channels

$N u=\left(\alpha D_{\mathrm{h}} / \lambda\right)$ Nusselt number

$P_{\text {leak }} \quad$ thermal leaks $(\mathrm{W})$

$P r \quad$ Prandtl number

$p \quad$ pressure $(\mathrm{Pa})$

$\Delta p \quad$ pressure loss $(\mathrm{Pa})$

$\dot{Q}$ heat transfer rate (W)

$\dot{q} \quad$ heat flux $\left(\mathrm{W} \mathrm{m}^{-2}\right)$

$R_{\mathrm{a}} \quad$ tube roughness (m)

$R e=\left(\dot{m} D_{\mathrm{h}} / \mu_{1}\right)$ Reynolds number

$T$ temperature (K)

$\Delta T_{\mathrm{lm}} \quad \log$ mean temperature difference $(\mathrm{K})$

$\Delta T_{\text {sub }, \mathrm{i}}=T_{\mathrm{fl}, \mathrm{i}}-T_{\text {sat }}$ inlet subcooling $(\mathrm{K})$

$U \quad$ voltage $(\mathrm{V})$

$z \quad z$ coordinate $(\mathrm{m})$

Greek letters

$\alpha \quad$ heat transfer coefficient $\left(\mathrm{W} \mathrm{m}^{-2} \mathrm{~K}^{-1}\right)$

$\lambda$ thermal conductivity $\left(\mathrm{W} \mathrm{m}^{-1} \mathrm{~K}^{-1}\right)$

$\mu \quad$ dynamic viscosity (Pa s)

$\rho \quad$ mass density $\left(\mathrm{kg} \mathrm{m}^{-3}\right)$

$\xi \quad$ singular pressure loss coefficient

Subscripts

al aluminium

cr critical

f friction 


$\begin{array}{ll}\mathrm{fl} & \text { fluid } \\ \mathrm{G} & \text { global } \\ \mathrm{g} & \text { gravity } \\ \mathrm{i} & \text { inlet } \\ \mathrm{j} & \text { joule } \\ \mathrm{l} & \text { liquid } \\ \mathrm{M} & \text { averaged } \\ \mathrm{o} & \text { outlet } \\ \text { sing } & \text { singular } \\ \mathrm{W} & \text { wall } \\ z & \text { function of } z\end{array}$

Results found in the literature on heat transfer in mini-channels are often contradictory and operating conditions differ from one study to another, rendering the results difficult to compare. Detailed information on the geometry, like roughness, hydraulic diameter uniformity or the type of entrance, are often missing. Furthermore, correlations for flow boiling in large tubes (Chen [1], Shah [2], Liu and Winterton [3]) largely under-predict the performance of mini-channels, which is why new studies for single- and two-phase flows are needed. Thus the present study examines frictional pressure loss and heat transfer in industrial multi-port extruded tubes (MPE tubes) with R134a refrigerant and forced convection for a single liquid flow as well as for boiling flow in similar conditions to those encountered in air-conditioning systems. This work presents experimental friction factors and heat transfer coefficients obtained with a single-phase liquid flow in such mini-channels, in preparation for a future two-phase flow study.

Table 1 summarises the experimental conditions of previous studies on mini-channels. In the last column the critical Reynolds numbers from laminar to turbulent flow estimated by other authors are reported. Michallon [4] as well as Feldman [5] have studied adiabatic air flows in rectangular channels with small hydraulic diameters and obtained friction factors in agreement with the Shah and London correlation [6] for laminar flows and with the Blasius correlation for

Table 1

Summary of experimental conditions of previous studies

\begin{tabular}{lllll}
\hline Author & Fluid & Geometry $(\mathrm{mm})$ & $D_{\mathrm{h}}(\mathrm{mm})$ & $R e_{\text {cr }}$ \\
\hline Adams et al. [25] & Water & Circular & $0.76,1.09$ & - \\
Feldman [5] & Air & Rectangular & 1.66 & - \\
Garimella et al. [17] & Glycol & Rectangular & $1.74,2.21,3.02$ & $800-2000$ \\
Harms et al. [7] & Water & Rectangular & $0.4,1.92$ & $\approx 1500$ \\
Michallon [4] & Air & Rectangular & 1.99 & $500-2000$ \\
Peng and co-workers [9-14] & Water & Rectangular & $0.31-0.75$ & $200-700$ \\
Yan and Lin [8] & R134a & Circular & 2.00 & $\approx 2000$ \\
Yang and Webb [15] & R12 & Rectangular & $1.56,2.64$ & - \\
\hline
\end{tabular}


turbulent flows. Harms et al. [7] have studied single-phase water flow in horizontal rectangular mini-channels made of silicium and found friction factors very close to the predictions of Shah and London, whereas their transition from laminar to turbulent flow took place for a Reynolds number of about 1500. However, Yan and Lin [8] measured friction factors in laminar and turbulent flows significantly higher than the predictions of the Poiseuille and Blasius equations. The authors impute this to entry length effects or to tube roughness.

Peng and co-workers [9-14] obtained heat transfer coefficients increasing with Reynolds number for a laminar single-phase flow with water, while a constant heat transfer coefficient was expected. Nevertheless the heat transfer coefficient in the turbulent flow region was found to be quite well predicted by a modified Dittus-Boelter equation. Moreover, their transition Reynolds numbers ranged from 200 to 700 . Yang and Webb [15] showed that with a turbulent horizontal liquid flow of R12 in rectangular mini-channels the Petukhov correlation given by Incropera and DeWitt [16] was in good agreement with their heat transfer results. Recently, Garimella et al. [17] studied developing flows in mini-channels and found a transition Reynolds number between 800 and 2000 for the heat transfer coefficient.

\section{Experimental device}

The test loop, shown in Fig. 1, includes a liquid pump (10-100 1/h) and a glycol-water mixture circuit for heat evacuation. The test section, shown in Fig. 2, consists of an industrial flat tube

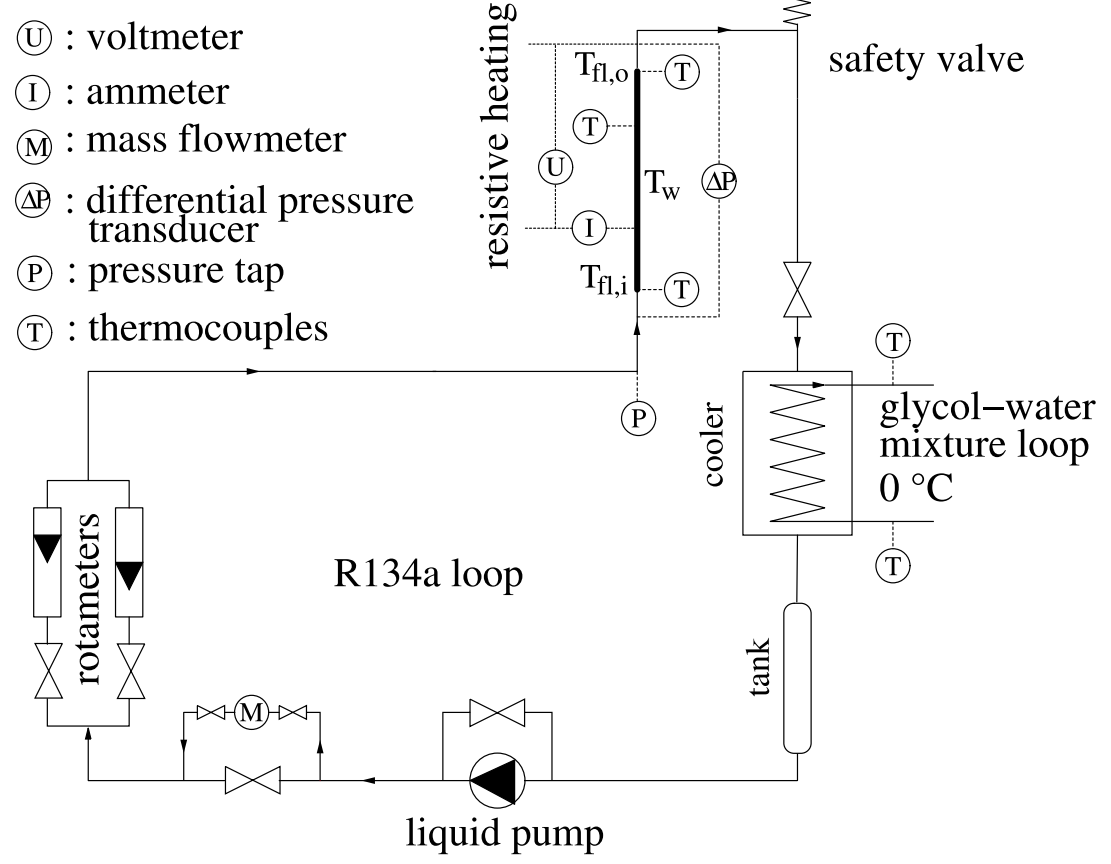

Fig. 1. Test loop. 

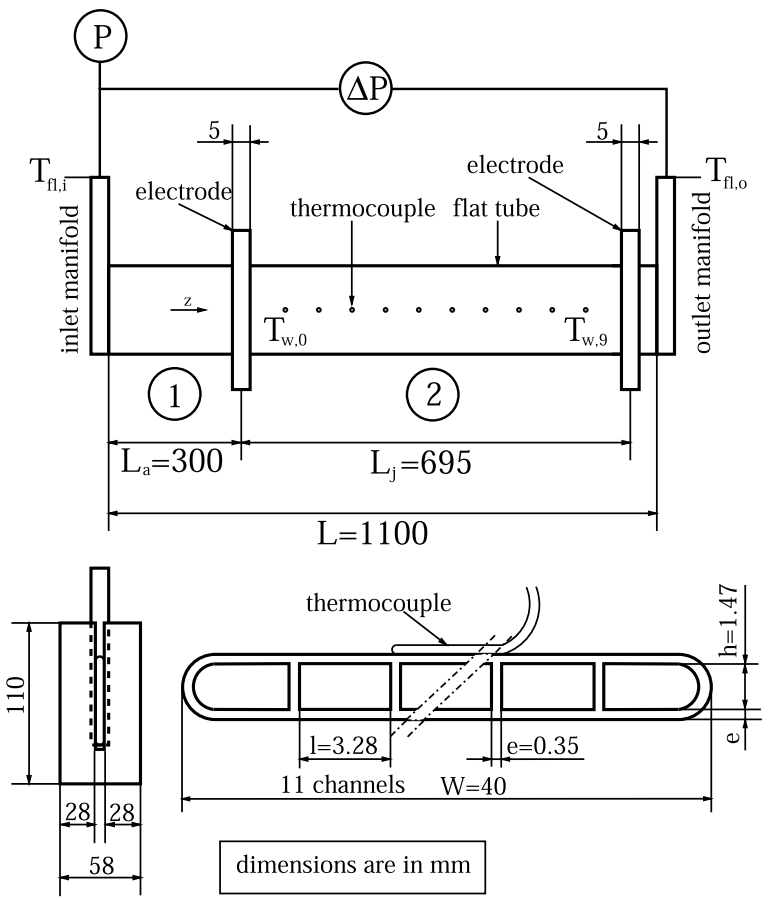

Fig. 2. Test section, dimensions in $\mathrm{mm}$.

made of extruded aluminium and composed of 11 parallel rectangular channels $(3.28 \mathrm{~mm} \times 1.47$ $\mathrm{mm}$ ) with measured hydraulic diameter $2.01 \mathrm{~mm}$ and wall thickness $0.35 \mathrm{~mm}$. The inlet and outlet manifolds are $10 \mathrm{~mm}$ diameter tubes at $90^{\circ}$. The manifold diameter is five times higher than the channel hydraulic diameter to limit fluid distribution effects. The whole test section is thermally insulated with $40 \mathrm{~mm}$ thick wrapping foam. For heat transfer measurements the length $L_{\mathrm{j}}$ of the tube (zone (2))) was using thanks the Joule effect by passing an electric current (up to $2800 \mathrm{~A}$ ) from two brased electrodes through the tube wall. Before the heated region an adiabatic length $L_{\mathrm{a}}$ (zone (1)) was devised to ensure a fully developed flow. Experimental conditions are summarised in Table 2.

Fig. 2 shows the test section and instrumentation. Wall temperatures $T_{\mathrm{w}, j}(0<j<9)$ on the tube external surface were measured with $0.5 \mathrm{~mm}$ diameter calibrated type $\mathrm{E}$ thermocouples. Fluid inlet and outlet mixed mean temperatures (respectively $T_{\mathrm{fl}, \mathrm{i}}$ and $T_{\mathrm{fl}, \mathrm{o}}$ ) were measured with 1 $\mathrm{mm}$ diameter calibrated type $\mathrm{K}$ thermocouples in a $\mathrm{T}$ junction to ensure mixing. Calibration was carried out every $5 \mathrm{~K}$ between 268 and $333 \mathrm{~K}$ with a Rosemount 162-CE platinum thermometer. The thermocouples used for wall temperature measurements were equally spaced and fixed with aluminium adhesive on the tube surface. Due to the high thermal conductivity of the aluminium and the low thickness of the tube walls, the measured temperature is equal to the wall temperature in contact with the fluid (difference estimated less than $0.01 \mathrm{~K}$ ). The fluid inlet pressure was measured with calibrated Rosemount type II absolute pressure sensors. Two differential pressure sensors calibrated from 0 to $7.6 \mathrm{kPa}$ and $40.5 \mathrm{kPa}$ measure the pressure loss through the test section. A Rosemount micro-motion coriolis flowmeter is used to measure the mass flux of R134a 
Table 2

Operating conditions

\begin{tabular}{lll}
\hline & Value & Error \\
\hline$D_{\mathrm{h}}(\mathrm{mm})$ & 2.01 & $\pm 3 \%$ \\
$L(\mathrm{~mm})$ & 1100 & $\pm 0.4 \%$ \\
Friction factor & & \\
$\dot{m}\left(\mathrm{~kg} \mathrm{~m}^{-2} \mathrm{~s}^{-1}\right)$ & $35-800$ & $\pm 4 \%$ \\
$T_{\mathrm{w}}, T_{\mathrm{fl}}(\mathrm{K})$ & $273-281$ & $\pm 0.1 \mathrm{~K}$ \\
$\Delta T_{\text {sub,i }}(\mathrm{K})$ & $\approx 40$ & - \\
$p_{\mathrm{i}}(\mathrm{kPa})$ & $\approx 1700$ & - \\
$\Delta p(\mathrm{kPa})$ & $0.3-9.3$ & $\pm 3 \%$ \\
$\mathrm{Flow}$ & Horizontal & \\
$H_{\text {Heat transfer coefficient }}$ & & $\pm 3 \%$ \\
$\dot{m}\left(\mathrm{~kg} \mathrm{~m}{ }^{-2} \mathrm{~s}^{-1}\right)$ & $28-715$ & $\pm 3 \%$ \\
$\dot{q}\left(\mathrm{~kW} \mathrm{~m}{ }^{-2}\right)$ & $0.84-22$ & $\pm 0.1 \mathrm{~K}$ \\
$T_{\mathrm{w}}, T_{\mathrm{fl}}(\mathrm{K})$ & $270-332$ & - \\
$\Delta T_{\text {sub,i }}(\mathrm{K})$ & $\approx 70$ & \\
$p_{\mathrm{i}}(\mathrm{kPa})$ & $\approx 2000$ & \\
Flow & Ascendant & \\
\hline
\end{tabular}

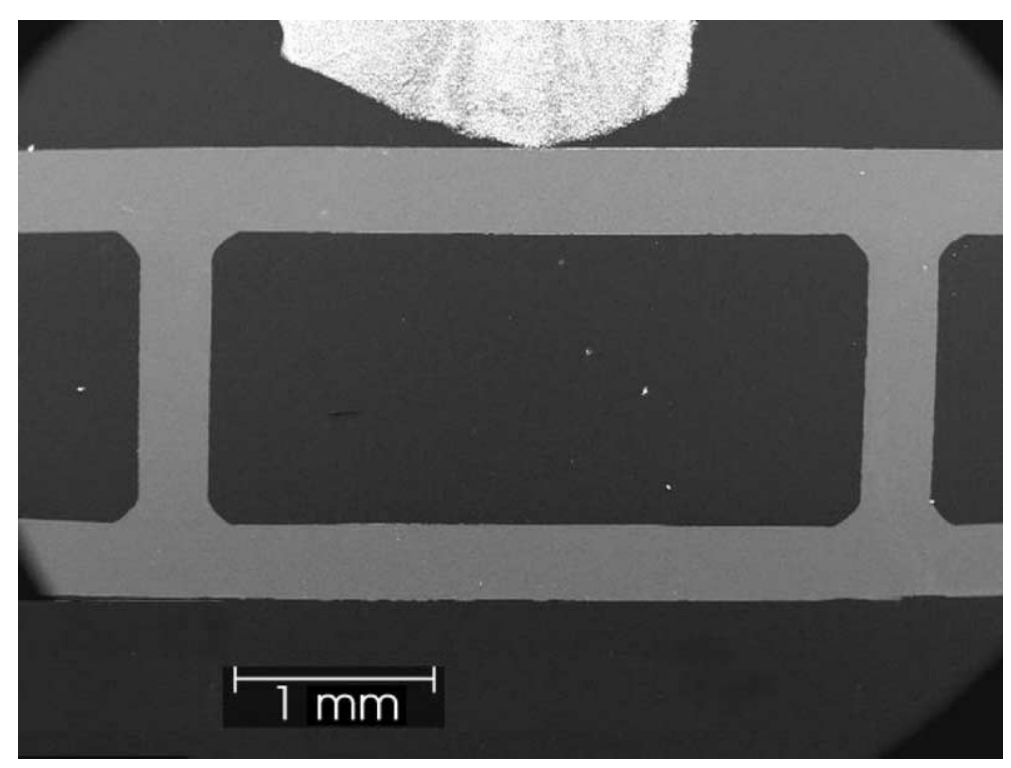

Fig. 3. Electron microscope image.

downstream of the pump. The heating voltage $U$ and current $I$ were measured directly via a HP 3421A multiplexer.

Heat flux was varied for every mass flow rate in order to keep the fluid temperature rise between 30 and $40 \mathrm{~K}$. The variation of $\operatorname{Pr}^{1 / 3}$ due to this temperature rise is about $2 \%$ and it was not taken into account. Steady state values were monitored using the Hewlett Packard 3421A with a $30 \mathrm{~min}$ time lapse between each mass flow rate or heat flux change. Averaging occurred after every 20 
values and uncertainties were calculated according to the Kline and Mc Clintock [18] and Moffat $[19,20]$ methods. The uncertainty on temperature measurements was estimated at $\pm 0.1 \mathrm{~K}$. Other uncertainties are reported in Table 2. The total electrical power dissipated in the test section was calculated as the product of voltage and current. The variation of R134a thermophysical properties with temperature were calculated with the REFPROP 6.01 software.

Fig. 3 shows a photography of the mini-channels. The determination of the channel dimensions was carried out using electron microscopy and permitted their measurement with accuracy. Furthermore roughness measurements were carried out. The dimensions are $\bar{l}=3.28 \pm 0.02 \mathrm{~mm}$, $\bar{h}=1.47 \pm 0.02 \mathrm{~mm}$ and $\bar{R}_{\mathrm{a}}<1 \mu \mathrm{m}$, yielding $\bar{D}_{\mathrm{h}}=2.01 \pm 0.06 \mathrm{~mm}$.

\section{Friction factor}

Pressure loss measurements were performed in adiabatic conditions. The total pressure loss through the test section is

$$
\Delta p_{\text {exp }}=\Delta p_{\mathrm{f}}+\Delta p_{\text {sing }}
$$

with the frictional pressure loss

$$
\Delta p_{\mathrm{f}}=\frac{\dot{m}^{2}}{2 \rho_{1}} 4 f \frac{L}{D_{\mathrm{h}}}
$$

and the singular pressure loss

$$
\Delta p_{\text {sing }}=\frac{\dot{m}^{2}}{2 \rho_{1}} \xi
$$

Since pressure loss measurements were performed with a horizontal configuration, there is no gravitational pressure loss. Thus, the friction factor can be expressed as

$$
4 f+\xi \frac{D_{\mathrm{h}}}{L}=\frac{2 \rho_{1} D_{\mathrm{h}}}{\dot{m}^{2} L} \Delta p_{\exp } .
$$

The frictional pressure loss in the straight sections of the manifolds is about $0.3 \%$ of the total pressure loss. This effect is therefore negligible. In order to assess the singular pressure loss coefficient caused by the $\mathrm{T}$ junctions in the manifolds, Eq. (4) multiplied by $R e$ was plotted against the Reynolds number for $900<R e<1400$ in Fig. 4. In the laminar regime the friction factor should not depend on the tube roughness so that the inlet and outlet effects can be isolated in this region. The linearity of the points on Fig. 4 indicates that Eq. (4) is equivalent to

$$
4 f R e+\xi \frac{D_{\mathrm{h}}}{L} R e=b+a R e,
$$

$a$ and $b$ being numerical constants. The singular pressure loss coefficient should not vary with $R e$ but with geometry only. Indeed, according to Idel'cik [21], $\xi$ depends only on the flow surfaces and fluid speed ratios in each branch of the $\mathrm{T}$ junctions in the manifolds. The flow surfaces ratio is a function of the junction geometry only and, if the mass flow rate is evenly distributed, the fluid speed ratio is independent of $R e$. Thus it is possible to identify the right and left hand terms of 


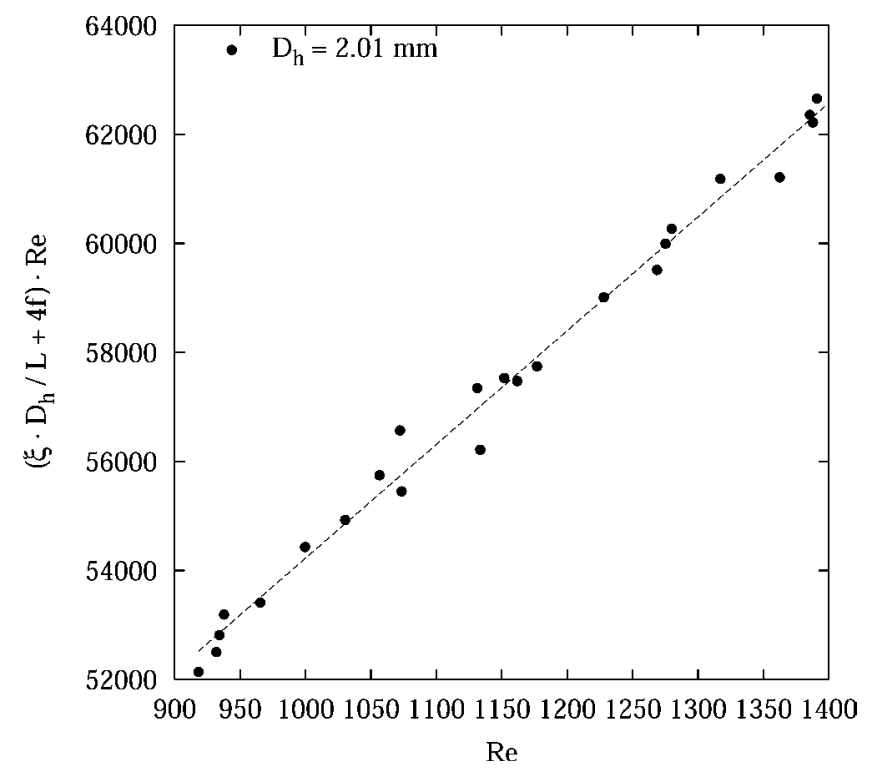

Fig. 4. Determination of the singular pressure loss coefficient.

Eq. (5) according to increasing powers of $R e$. Since $\xi D_{\mathrm{h}} / L$ is constant this identification necessarily gives

$$
\text { 4f } R e=b \quad \text { and } \quad \xi \frac{D_{\mathrm{h}}}{L}=a .
$$

The singular pressure loss coefficient taking into account inlet and outlet effects can be calculated with this method and the $4 f R e$ product is found to be constant. Linear regression of the uncertainties leads to $\xi=21 \pm 0.5$ and $4 f R e=61 \pm 10$. The factor $4 f$ evaluated with Eq. (4) can now be plotted as a function of $R e$ (see Fig. 5), together with the Shah and London [6] correlation for a laminar flow in a rectangular channel with $h / l=0.45$,

$$
4 f=\frac{63.8}{R e}
$$

and the Filonenko correlation given by Incropera and DeWitt [16] for turbulent flow,

$$
4 f=(0.790 \ln (R e)-1.64)^{-2} \text {. }
$$

The transition is clearly visible for $R e \approx 2000$. In the laminar regime, for $900<R e<1800$, the friction factor is in good agreement with Eq. (7). In the developing turbulent regime, for $2000<R e<5500$, the friction factor is under-predicted by Eq. (8) but is very close if uncertainties are taken into account. The Colebrook-White [21] equation on Fig. 5 shows that a $20 \mu \mathrm{m}$ roughness could explain higher friction factors, but that does not agree with our roughness measurements which were less than $1 \mu \mathrm{m}$. Table 3 indicates uncertainties on $4 f$ and Re. Finally results in both the laminar and turbulent regime are in good agreement with studies in conventional tubes. The transition Reynolds number to the turbulent regime is about 2000, very like the usual threshold in conventional tubes. 


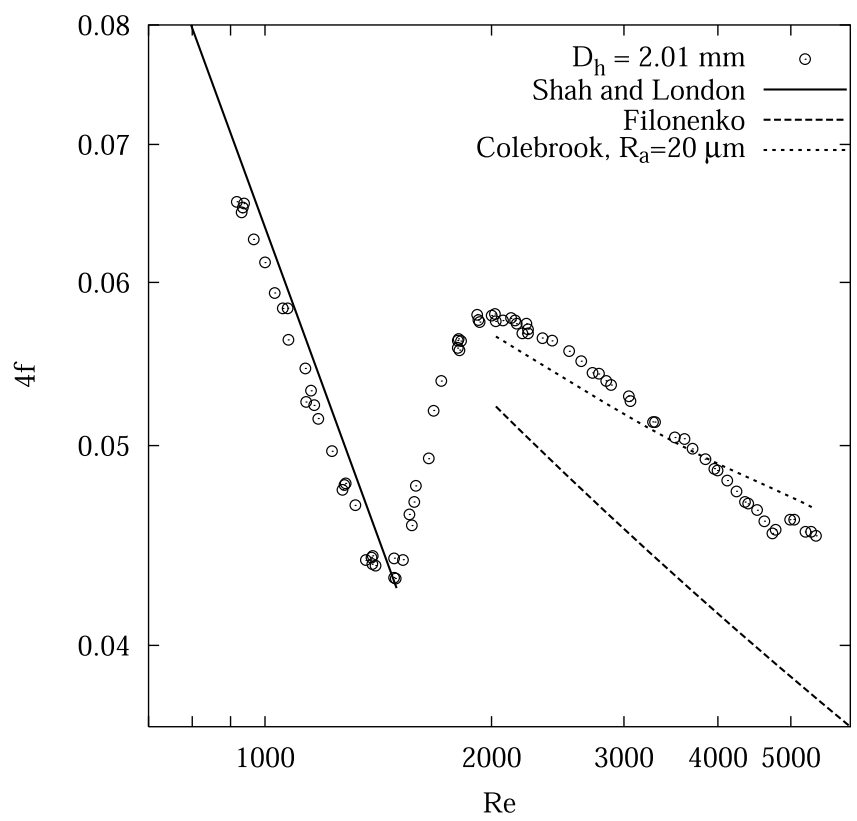

Fig. 5. Friction factor versus Reynolds number.

Table 3

Uncertainties on $4 f, R e$ and $N u$

\begin{tabular}{|c|c|c|c|}
\hline \multicolumn{2}{|c|}{ Friction factor } & \multicolumn{2}{|c|}{ Heat transfer } \\
\hline$\Delta 4 f / 4 f$ & $\Delta R e / R e$ & $\Delta N u / N u$ & $\Delta R e / R e$ \\
\hline $\pm 8-14 \%$ & $\pm 4 \%$ & $\pm 3-7.5 \%$ & $\pm 3.5 \%$ \\
\hline
\end{tabular}

\section{Heat transfer coefficient}

Since aluminium has a high thermal conductivity $\left(\approx 200 \mathrm{~W} \mathrm{~m}^{-1} \mathrm{~K}^{-1}\right)$ it is assumed that the electrical power dissipated in the metal produces an equal heat flux on every channel wall. Thus the heat flux is calculated using

$$
\dot{q}=\frac{U I}{2 N(l+h) L_{\mathrm{j}}} .
$$

The fluid temperature at position $z$ is calculated via an energy balance giving

$$
T_{\mathrm{fl}}(z)=T_{\mathrm{fl}, \mathrm{i}}+\frac{U I}{\dot{M} c_{p, 1} L_{\mathrm{j}}} z .
$$

Three different heat transfer coefficients, a local, an averaged and a global one, were determined. The local heat transfer coefficient and Nusselt number are defined as 


$$
N u_{z}=\frac{\alpha_{z} D_{\mathrm{h}}}{\lambda_{\mathrm{l}}(z)} \quad \text { and } \quad \alpha_{z}=\frac{\dot{q}}{T_{\mathrm{w}}(z)-T_{\mathrm{fl}}(z)}
$$

with

$$
\lambda_{1}(z)=\lambda_{1}\left(T_{\mathrm{fl}}(z)\right)
$$

The average Nusselt number is defined as

$$
N u_{\mathrm{M}}=\frac{1}{10} \sum_{i=0}^{9} N u_{i}
$$

Finally, the global heat transfer coefficient and Nusselt number are calculated using

$$
N u_{\mathrm{G}}=\frac{\alpha_{\mathrm{G}} D_{\mathrm{h}}}{\bar{\lambda}_{\mathrm{l}}} \quad \text { and } \quad \alpha_{\mathrm{G}}=\frac{\dot{q}}{\Delta T_{\mathrm{lm}}},
$$

with $\bar{\lambda}_{1}$ the fluid thermal conductivity averaged along the test section. The log mean temperature difference $\Delta T_{\operatorname{lm}}$ is defined as

$$
\Delta T_{\operatorname{lm}}=\frac{\left(T_{\mathrm{w}, 0}-T_{\mathrm{fl}, 0}\right)-\left(T_{\mathrm{w}, 9}-T_{\mathrm{fl}, 9}\right)}{\ln \left(\frac{T_{\mathrm{w}, 0}-T_{\mathrm{fl}, 0}}{T_{\mathrm{w}, 9}-T_{\mathrm{fl}, 9}}\right)} .
$$

Accordingly, the local and global Reynolds numbers are

$$
R e_{z}=\frac{\dot{m} D_{\mathrm{h}}}{\mu_{1}(z)}, \quad R e=\frac{\dot{m} D_{\mathrm{h}}}{\bar{\mu}_{1}} .
$$

The energy balance was checked and thermal leaks, defined by

$$
P_{\text {leak }}=\dot{M} c_{p, 1}\left(T_{\mathrm{fl}, \mathrm{o}}-T_{\mathrm{fl}, \mathrm{i}}\right)-U I
$$

were found to be less than $5 \%$ of the injected power, and less than $3 \%$ for $85 \%$ of the data points. Table 3 presents uncertainty values on $N u$ and $R e$.

It was verified that mixed convection could not occur. Indeed, according to Metais and Eckert [22], over the present Reynolds number range, the mixed convection should occur for $G r \operatorname{Pr} D_{\mathrm{h}} /$ $L_{\mathrm{j}}>3000$, while the value for the present experiment was approximately 22 . Thus only forced convection can occur.

In Fig. 6, the global and averaged Nusselt numbers are plotted against the Reynolds number. Both show the same trends, and as with the friction factor, transition from the laminar to the turbulent regime occurs for $R e \approx 2000$. In the turbulent regime the global Nusselt number agrees with the Gnielinsky [23] correlation, modified to take into account the thermal entry length effect

$$
N u=\frac{(f / 2)(\operatorname{Re}-1000) \operatorname{Pr}}{1+12.7 \sqrt{f / 2}\left(\operatorname{Pr}^{2 / 3}-1\right)}\left[1+\left(\frac{D_{\mathrm{h}}}{L_{\mathrm{j}}}\right)^{2 / 3}\right],
$$

with $f$ calculated using Eq. (8). This correlation is valid for $2300<\operatorname{Re}<10^{6}$ and $0.6<\operatorname{Pr}<10^{5}$. The Dittus-Boelter correlation given by Incropera and DeWitt [16]:

$$
N u=0.023 \operatorname{Re}^{0.8} \operatorname{Pr}^{1 / 3},
$$

devised for $\operatorname{Re}>10000,0.7<\operatorname{Pr}<16700, L_{\mathrm{j}} / D_{\mathrm{h}}>10$, is not valid here. 


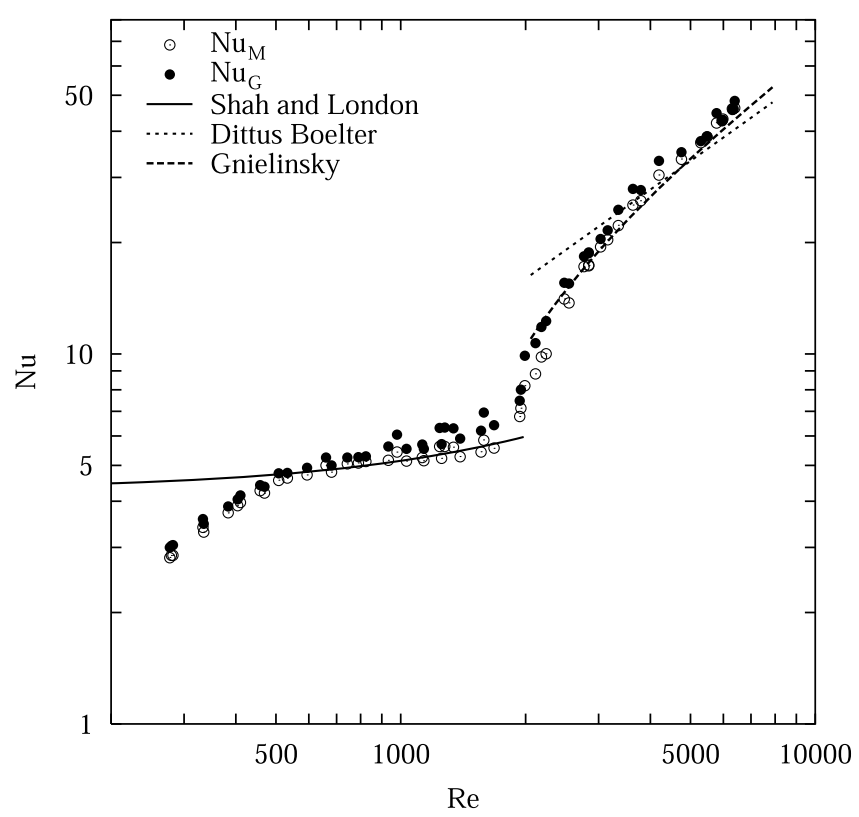

Fig. 6. Average and global Nusselt number versus global Reynolds number.

In the laminar regime, for $500<R e<2000$, the global Nusselt number is well predicted by the Shah and London [6] tabulated values for a thermally developing flow. The thermal entry length for constant heat flux heating is $L_{\mathrm{th}} / D_{\mathrm{h}}=0.0431 \operatorname{Re} \operatorname{Pr}$ [24]. In the present experiment, for $300<\operatorname{Re}<2000, L_{\mathrm{j}} / D_{\mathrm{h}}=343$ and $50<L_{\text {th }} / D_{\mathrm{h}}<320$. Thus it is possible that the flow does not reach a steady state profile. As a result $N u$ slightly increases with $R e$ in the laminar region.

For $R e<500, N u$ falls below the Shah and London [6] curve. This effect is probably due to longitudinal conduction which happens with constant heat flux heating because of the temperature gradient along the test section. The Biot number defined as

$$
B i=\frac{\alpha L_{\mathrm{j}}}{\lambda_{\mathrm{al}}}
$$

is about 0.7 when $R e<500$ so that conductive and convective effects are both relevant. Furthermore, as the aluminium cross-section of the flat tube is small, the longitudinal heat transfer rate

$$
\dot{Q}=\lambda_{\mathrm{al}} \frac{T_{\mathrm{w}, 9}-T_{\mathrm{w}, 0}}{z_{9}-z_{0}} A_{\mathrm{al}}
$$

is very small. One particular datum should be examined. For $R e=260, \dot{Q}$ was calculated as 0.48 $\mathrm{W}$, with $T_{\mathrm{w}, 0}-T_{\mathrm{fl}, 0}=6 \mathrm{~K}, T_{\mathrm{w}, 9}-T_{\mathrm{fl}, 9}=8.5 \mathrm{~K}, U I=62 \mathrm{~W}, P_{\text {leak }}=1 \mathrm{~W}$ and $A_{\mathrm{al}}=40 \mathrm{~mm}^{2}$. Moreover according to the Shah and London [6] prediction the values should be $\dot{Q}=0.46 \mathrm{~W}$, $T_{\mathrm{w}, 0}-T_{\mathrm{fl}, 0}=4.2 \mathrm{~K}$ and $T_{\mathrm{w}, 9}-T_{\mathrm{fl}, 9}=5 \mathrm{~K}$. Surprisingly, with even a $2 \%$ change in thermal leakage (as little as $0.02 \mathrm{~W}$ in the longitudinal heat transfer rate) $N u_{9}$ will drop by $35 \%$. As a consequence, even with thermal leaks lower than $5 \%$, one can find Nusselt numbers increasing with the 


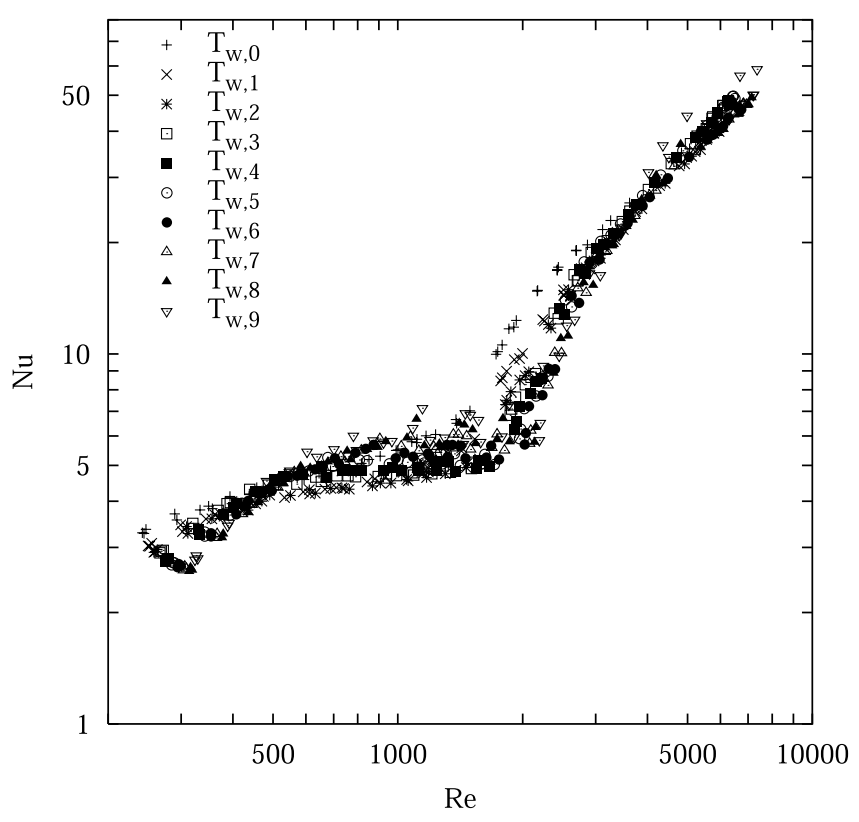

Fig. 7. Local Nusselt number versus local Reynolds number.

Reynolds number in the laminar regime because of longitudinal conduction but it is most probable that this is merely an artifact of the measurement method.

This is further highlighted in Fig. 7 where the local Nusselt numbers are plotted against the local Reynolds number. For $R e<500$, the local Nusselt number $N u_{z}$ decreases along the test section as, in Fig. 6, the average Nusselt number $N u_{\mathrm{M}}$ strongly decreases with decreasing $R e$. The transition $R e=500$ is the Reynolds number below which the fluid and wall temperature profiles are no longer parallel.

Peng and Peterson [11] proposed a correlation for the laminar Nusselt number in rectangular micro-channels which can be expressed for the present geometry as follows:

$$
N u=0.10 \operatorname{Re}^{0.62} \operatorname{Pr}^{1 / 3} \text {. }
$$

It is clear from Fig. 8 that this equation over-predicts the data presented here. Peng and co-workers [10,13] found $N u$ increasing with $R e$ and they argue that the transition in their minichannels is much earlier than the traditional transition at $R e=2000$ whereas present measurements clearly show a transition for $R e \approx 2000$. However their correlation was established for hydraulic diameters up to $0.75 \mathrm{~mm}$ and for much shorter channels than here. However in their study $60<L_{\mathrm{j}} / D_{\mathrm{h}}<300$ which is very close to the present experiment, thus the thermal entry length cannot explain the inconsistency with the data presented here. Moreover the authors calculated their Reynolds numbers with the inlet fluid properties while the fluid temperature rise along the channels was not known. Thus the increase in Reynolds number between inlet and outlet cannot be estimated with any certainty.

The Adams et al. [25] correlation is based on the Gnielinsky [23] correlation with a corrective factor to take into account confinement effects. It was devised for $D_{\mathrm{h}}<1.09 \mathrm{~mm}$ and fails to 


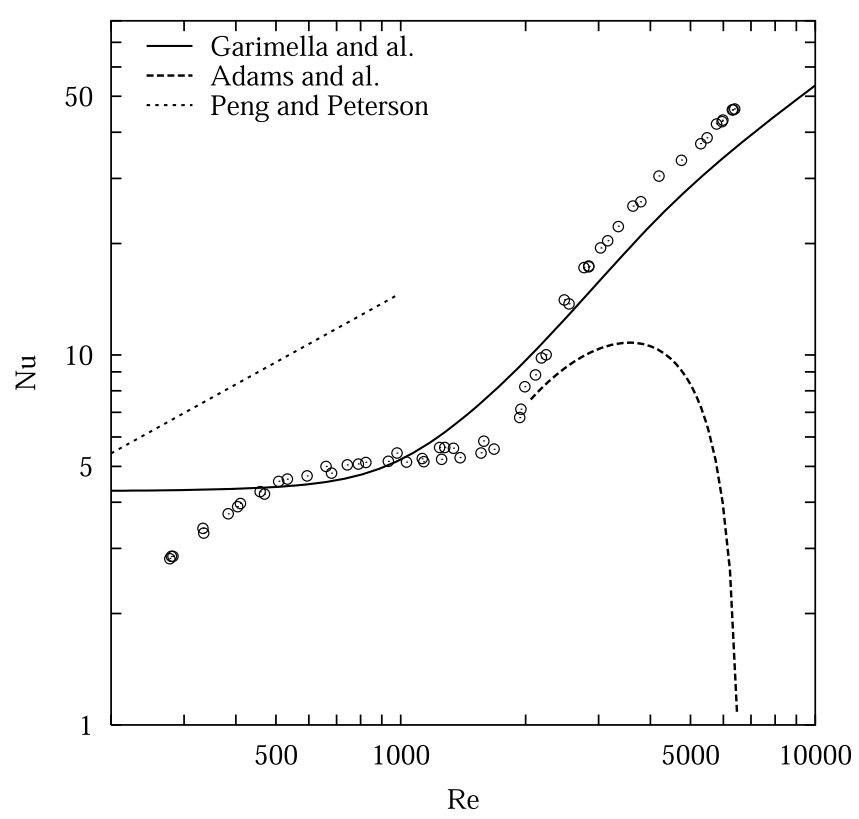

Fig. 8. Comparison with literature correlations for mini-channels.

predict the present data. The mathematical function chosen for this correction factor decreases sharply when $D_{\mathrm{h}}>1.09 \mathrm{~mm}$.

The best predictions are obtained with the Garimella et al. [17] correlation which is mainly based on the Shah and London [6] results in the laminar regime and the Gnielinsky [23] correlation in the turbulent regime. The authors developed an expression valid for both regimes, taking into account the thermal entry length.

\section{Conclusions}

The behaviour of mini-channels, in terms of heat transfer and frictional pressure loss, has been found to be very close to that in conventional tubes. In particular the laminar-turbulent transition occurs for $R e \approx 2000$ and the value of the friction factor and heat transfer coefficients are well predicted by correlations established for conventional tubes in the range $500<R e<7000$. Thus the validity range of the Shah and London [6] predictions and the Gnielinsky [23] correlation can be extended to our experimental conditions in this interval. For $R e<500$ it was found that the Nusselt number strongly decreased with decreasing Reynolds number as reported in some studies, but this is probably due to longitudinal conduction effects which are seldom checked. Shah and London [6] report that this effect causes a decrease of the Nusselt number and requires heavy mathematical work to model. Constant wall temperature measurements might prevent this effect but they are difficult to set-up and less accurate than constant heat flux conditions.

Smaller tubes (1.17 and $0.77 \mathrm{~mm}$ hydraulic diameter) are being tested to further verify some of these conclusions, and a flow boiling study in the same tubes is in progress to highlight confinement effect on boiling heat transfer. 


\section{References}

[1] J. Chen, Correlation for boiling heat transfer to saturated fluids in convective flow, Industrial Engineering and Chemistry Process Design and Development 5 (3) (1966) 322-329.

[2] M. Shah, A new correlation for heat transfer during boiling flow through pipes, Transactions of the ASHRAE 82 (1976) 66-86.

[3] Z. Liu, R. Winterton, A general correlation for saturated and subcooled flow boiling in tubes and annuli, based on a nucleate pool boiling equation, International Journal of Heat and Mass Transfer 34 (11) (1991) 2759-2766.

[4] E. Michallon, Étude du comportement de l'écoulement dans des canaux de section rectangulaire constitués de plaques et d'ailettes brasées, Ph.D. thesis, Université Nancy I en mécanique énergétique, Novembre 1993.

[5] A. Feldman, De l'ébullition en convection forcée dans des canaux d'échangeurs à plaques et ailettes, Ph.D. thesis, Université Henry Poincaré, Nancy I, 1996.

[6] R. Shah, A. London, Laminar Flow Forced Convection in Ducts, Academic Press, 1978.

[7] T. Harms, M. Kazmierczak, F. Gerner, Developing convective heat transfer in deep rectangular microchannels, International Journal of Heat and Fluid Flow 20 (1999) 149-157.

[8] Y. Yan, T. Lin, Condensation heat transfer and pressure drop of refrigerant R134a in a small pipe, International Journal of Heat and Mass Transfer 42 (1999) 697-708.

[9] X. Peng, G. Peterson, Forced convection heat transfer of single-phase binary mixtures through microchannels, Experimental Thermal and Fluid Science 12 (1996) 99-104.

[10] B. Wang, X. Peng, Experimental investigation on liquid forced-convection heat transfer through microchannels, International Journal of Heat and Mass Transfer 37 (4) (1994) 73-82.

[11] X. Peng, G. Peterson, Convective heat transfer and flow friction for water flow in microchannels structures, International Journal of Heat and Mass Transfer 39 (12) (1996) 2599-2608.

[12] X. Peng, B. Wang, Forced convection and flow boiling heat transfer for liquid flowing through microchannels, International Journal of Heat and Mass Transfer 36 (14) (1993) 3421-3427.

[13] X. Peng, B. Wang, G. Peterson, Experimental investigation of heat transfer in flat plates with rectangular microchannels, International Journal of Heat and Mass Transfer 38 (1) (1995) 127-137.

[14] X. Peng, G. Peterson, The effect of thermofluid and geometrical parameters on convection of liquids through rectangular microchannels, International Journal of Heat and Mass Transfer 38 (4) (1995) 755-758.

[15] C. Yang, R. Webb, Condensation of R12 in small hydraulic diameter extruded aluminium tubes with and without micro-fins, International Journal of Heat and Mass Transfer 39 (4) (1996) 791-800.

[16] F. Incropera, D. DeWitt, Fundamentals of Heat and Mass Transfer, fourth ed., John Wiley and Sons, 1994.

[17] S. Garimella, W. Dowling, M.V.D. Veen, J. Killion, The effect of simultaneously developing flow on heat transfer in rectangular tubes, Heat Transfer Engineering 22 (6) (2001) 12-25.

[18] S. Kline, F. McClintock, Describing uncertainties in single-sample experiments, Mechanical Engineering (1953) 3-8.

[19] R. Moffat, Contributions to the theory of single-sample uncertainty analysis, Journal of Fluids Engineering 104 (1982) 250-261.

[20] R. Moffat, Using uncertainty analysis in the planning of an experiment, Journal of Fluids Engineering 107 (1985) $173-182$.

[21] I. Idel'cik, Memento des pertes de charge, Eyrolles, 1979.

[22] B. Metais, E. Eckert, Forced, mixed and free convection regimes, Journal of Heat Transfer 86 (1964) 295.

[23] V. Gnielinski, New equations for heat and mass transfer in turbulent pipe and channel flow, International Chemical Engineering 16 (2) (1976) 359-368.

[24] J. Taine, J.-P. Petit, Transferts thermiques, Dunod Université, 1989.

[25] T. Adams, S. Abdel-Khalik, S. Jeter, Z. Qureshi, An experimental investigation of single-phase forced convection in microchannels, International Journal of Heat and Mass Transfer 41 (6-7) (1998) 851-857. 